\title{
PREVENTION OF OBSTRUCTION OF NASOPHARYNGEAL CPAP TUBES BY ADEQUATE HUMIDIFICATION OF INSPIRED GASES
}

\author{
H.F.L. Pollett and W.D. Reid
}

Continuous positive airway pressune (CPAP) is a useful method of treating idiopathic respiratory distress syndrome (IRDS). It increases the functional residual capacity (FRC) and also appears to cause reflex stimulation of ventilation.

CPAP can be applied by tracheal intubation, nasal prongs, head box with a tight neck seal, or nasopharyngeal intubation.

The latter method appears to be the most advantageous, particularly since it avoids laryngeal trauma with the potential tracheal stenosis associated with prolonged tracheal intubation. Nasopharyngeal CPAP is a logical continuation of the weaning sequence which includes controlled ventilation, intermittent mandatory ventilation (IMV), nasotracheal CPAP, nasopharyngeal CPAP, and finally extubation. This sequence allows a gradual withdrawal of ventilatory assistance which is tolerated by the distressed neonate.

Crusting and obstruction in the tubes occurred in the initial 12 infants in whom we used nasopharyngeal CPAP for longer than 24 hours. This obstruction frequently resulted in acute clinical deterioration.

The purpose of this paper is to show how easily this complication can be overcome by more adequate humidification of inspired gases. Twelve additional infants were studied using increased humidification.

\section{METHOD}

Two groups of 12 premature infants were studied. In the first group, the inspired gas temperature was $23^{\circ}$ to $26^{\circ} \mathrm{C}$. In the second group, the inspired gas temperature was $31^{\circ}$ to $33^{\circ} \mathrm{C}$.

Nasopharyngeal CPAP was provided to both groups by the following method:

Air and oxygen were mixed in a flow meter to achieve the desired $\mathrm{F}_{\mathrm{O}_{2}}$ and then passed through a Puritan-Bennett heated cascade humidifier to the infant. The expired gas flow from the infant was opposed by flow from the negative phase outlet of the Bird Mark VIII Ventilator through a Venturi orifice. Regulation of the negative phase flow on the Bird Mark VIII controlled the amount of CPAP generated.

A nasotracheal tube of the same size that would be used for tracheal intubation was passed through a nostril into the pharynx behind the tongue, but above the epiglottis. The chest was ausculated as the tube was passed until the characteristic humming sound associated with CPAP was heard. The tube was taped to the face

H.F.L. Pollett, B.Sc., M.D., Department of Anaesthesia, W.D. Reid, M.D., F.R.C.P.(C), Department of Paediatrics, Victoria Hospital, London, Ontario.

Canad. Anaesth. Soc. J., vol. 24, no. 5, September 1977 
to prevent slippage. Laryngoscopy was not necessary, but was helpful in placing the tube accurately. Gastric distention was prevented by the insertion of a nasogastric tube.

The temperature of the inspired gas was measured using either a Yellow Springs thermal probe or a Puritan-Bennett in-line thermometer inserted through a hole in the cap over the tracheal tube connector.

\section{Results}

In both groups of infants, nasopharyngeal CPAP caused a reduction in the number of apnoeic spells, an increase in $\mathrm{Po}_{2}$ and a decrease in $\mathrm{PCO}_{2}$.

However, in the group of infants who had inspired gas temperatures of $23^{\circ}$ to $26^{\circ} \mathrm{C}$, crusting and blockage of the tube invariably occurred within 24 hours. This caused a marked deterioration in the clinical status of the patient with hypoxia and apnoea. Chest X-rays showed subsegmental atelectasis secondary to mucous plugging.

In the second group of 12 infants, the inspired gas temperature was raised by the Puritan-Bennett cascade humidifier to $31^{\circ}$ to $33^{\circ} \mathrm{C}$. In these infants, the tubes could be maintained for up to four days with no evidence of crusting or obstruction.

At $31^{\circ}$ to $33^{\circ} \mathrm{C}$, in contrast to the lower temperatures, considerable condensation was noted in the inspiratory tubing, especially outside the incubator. However, this condensation did not cause any clinical or radiological evidence of pulmonary oedema.

\section{DisCussion}

The physics of humidification is frequently not appreciated by clinicians. The moisture content and vapour pressure of air saturated with water increases with higher temperatures at the constant atmospheric pressure of $760 \mathrm{~mm} \mathrm{Hg}{ }^{1}$ If the inspired gas is fully saturated at a room temperature of $21^{\circ} \mathrm{C}$ and is warmed to body temperature without the addition of further humidity, it will only be about 40 per cent saturated at its delivery point.

The large surface area and rich vasculature of the nose and nasal sinuses compensate for this problem. During normal inspiration, the temperature in the upper trachea is $34.6^{\circ} \mathrm{C}$ with 95 per cent saturation. However, if a tracheal tube is in place, the temperature at the carina is only $33.8^{\circ} \mathrm{C}$ and the relative humidity varies according to the temperature and saturation of the inspired gas as well as the length of time the tracheal tube has been in place.

Whether the patient is intubated or not, a countercurrent mechanism is set up. The cool dry inspired air is warmed and saturated, cooling and drying the airways. During expiration the warm wet alveolar gas warms and moistens the airways. Thus the nose, pharynx and trachea can recover up to 25 per cent of the heat and water: from the expired gas.

When nasopharyngeal CPAP is used, very little of the expired gas returns through the inspiratory tubing due to the high expiratory resistance built into the system in order to achieve CPAP. Instead, the gas escapes in a fairly constant 
stream through the nasopharynx and out either the opposite nostril or, if the pressure is sufficient, out the mouth. No countercurrent mechanism is set up. With dry inspired gas there will be considerable heat and moisture lost from the respiratory tract.

Several authors have pointed out the undesirable effects of inadequate humidity on mucociliary activity. ${ }^{3-5}$ In addition, the patient must provide the difference between the water vapour content of dry gas and fully saturated gas as it reaches the alveoli. The patient must expend 580 small calories for each gram of water converted into vapour for humidification. In small infants, the water and heat loss can account for a substantial part of the fluid loss and caloric requirements. Another untoward effect is increased viscosity of bronchial secretions.

On the other hand, excess humidity with saturated gases cause a rise in the specific airway resistance, hyperthermia, water overload, and hypoxaemia.

In view of this there seems to be little point in raising the temperature of the inspired gas above $31^{\circ} \mathrm{C}$, the temperature at which we found we no longer had problems with crusting and mucous plugging.

\section{SUMMARY}

Nasopharyngeal CPAP is a simple and useful technique for increasing FRC and stimulating respiration in small premature infants. However, as it is essentially a non-rebreathing technique, the gases used should be warmed and saturated to the level normally found in the pharynx with no artificial airway present $\left(31^{\circ}\right.$ to $33^{\circ} \mathrm{C}, 90$ per cent plus relative humidity). If this is not done, crusting, mucous plugging, atelectasis, hypoxia, and infection will occur rapidly. Excess humidity should also be avoided.

\section{RÉSUMÉ}

Une CPAP administrée par canule nasopharyngée représente un moyen simple et efficace d'augmenter la capacité résiduelle fonctionnelle et de stimuler la respiration des petits prématurés. Cependant, il est important de réaliser qu'il s'agit d'une technique sans réinspiration. En conséquence, les gaz devraient être réchauffés et humidifiés de manière à retrouver les mêmes conditions que celles existant normalement dans le pharynx, soit une température de $31^{\circ}$ à $33^{\circ} \mathrm{C}$ et une humidité relative plus grande que 90 pour cent. Si on ne le fait pas, il y a formation rapide de croûtes, de bouchons muqueux et d'atélectasie conduisant à l'hypoxie et l'infection. On devrait cependant éviter une humidité excessive.

\section{REFERENCES}

1. Dick, W. Aspects of humidification. Requirements and techniques. Int. Anesthesiol. Clin. 12 (4) : $217-39$ (winter 1974 ).

2. Reynolos, F.B. Humidification and humidifiers. Int. Anesthesiol. Clin. 12 (3): 79-93 (fall 1974).

3. Mercke, $U$. The influence of varying air humidity on mucociliary activity. Acta Otolaryngology $79:$ 133-39 (1975).

4. Marfatia, S., Donohole, P.K., \& Henderen, W.H. Effect of dry and humidified gases on the respiratory epithelium in rabbits. Journal of Pediatric Surg. 10: 583-592 (1975).

5. Hinsch, J.A., Toknyen, J.L., Robinson, M.J., \& SockNen, M.A. Effects of dry air and subsequent humidification or tracheal mucous velocity in dogs. Journal of Applied Physiology, 39: 242-245 (1975). 